\title{
RELAÇÃO PROFESSOR-ALUNO NO PROJETO DE EXTENSÃO SECRETARIADO EXECUTIVO EM DEBATE
}

\author{
J. C. A. Filho ${ }^{1}$; Ana Maria Iorio Dias ${ }^{2}$, Joelma Soares da Silva ${ }^{3}$, Romana Fátima Rodrigues de Sousa ${ }^{4}$, \\ Conceição de Maria Pinheiro Barros ${ }^{5}$ \\ ${ }^{1}$ Acadêmico do Curso de Secretariado Executivo da UFC. (UFC). E-mail cardosotecateneu @ gmail.com; ${ }^{2}$ Doutora em Educação pela \\ Universidade Federal do Ceará (UFC). E-mail: ana.iorio@yahoo.com.br; ${ }^{3}$ Mestre em Biologia pela Universidade Federal do Maranhão. E- \\ mail: joelma.soares@ufc.br; ${ }^{4}$ Acadêmica do Curso de Secretariado Executivo da Universidade Federal do Ceará. E-mail: \\ romanafatimasousa@yahoo.com.br; ${ }^{5}$ Coordenadora do projeto de extensão da Universidade Federal do Ceará. E-mail: conceicaompb@ufc.br
}

Artigo submetido em Julho/2016 e aceito em Outubro/2016

\section{RESUMO}

A educação em Secretariado Executivo tem sido um dos enfoques das pesquisas na área, tendo em vista a busca por qualidade na formação desse profissional. Este trabalho tem como objetivo relatar um dos assuntos discutidos no projeto de extensão "Secretariado Executivo em Debate" na linha de pesquisa educação em Secretariado Executivo: a afetividade na relação professor-aluno. Metodologicamente, desenvolveu-se uma pesquisa qualitativa e descritiva, por meio da técnica de análise fílmica. Para tanto, foram selecionadas cenas do filme "Ao mestre com carinho 2". A análise foi desenvolvida por meio de discussão acerca do citado filme, a partir de uma interpretação teórica. Concluiu-se que o filme retrata os desafios que o professor pode enfrentar para contribuir para a formação intelectual e humana dos alunos, destacando que a afetividade pode ser fator preponderante para os processos de ensinar e aprender de modo que o aluno seja capaz de transformar a sua realidade. Por outro lado, os docentes denotaram que sua formação não aborda conhecimentos pedagógicos, porém, sentem a necessidade de desenvolver uma relação mais próxima com os alunos.

PALAVRAS-CHAVE: Educação; Relação professor-aluno; Análise Fílmica; Secretariado Executivo.

\section{RELATION BETWEEN STUDENT-PROFESSOR OF THE EXTENSION}

\section{PROJECT EXECUTIVE SECRETARIAT IN DISCUSSION}

\begin{abstract}
Education in the Executive Secretariat has been one of the approaches of the researches in the area, in view of the search for quality in the formation of this professional. This paper aims to report one of the topics discussed in the project "Executive Secretariat in Debate" in the research line education in Executive Secretariat: the affectivity in the teacher-student relationship. Methodologically, a qualitative and descriptive research was developed, through the technique of filmic analysis. For that,
\end{abstract}

scenes from the movie "Ao mestre com carinho 2" were selected. The analysis was developed through a discussion about the aforementioned film, based on a theoretical interpretation. It was concluded that the film portrays the challenges that the teacher can face to contribute to the intellectual and human formation of the students, noting that affectivity can be a preponderant factor for the processes of teaching and learning so that the student is able to transform the your reality.

KEYWORDS: Design. Crafts. Clothing 


\title{
INTRODUÇÃO
}

A educação em Secretariado Executivo tem sido um dos enfoques das pesquisas na área (NÓBREGA; ADELINO, 2012; BARROS; SILVA; BARROS, 2016; BARROS; SILVA; DIAS, 2016), tendo em vista a busca por qualidade na formação desse profissional. As investigações centram-se, entre outros temas, na formação docente e nas contribuições da pesquisa para a área. Neste texto, destaca-se o impacto do vínculo afetivo na relação professor-aluno no desenvolvimento acadêmico dos graduandos, a partir de discussões desenvolvidas no "Secretariado Executivo em Debate". Trata-se de um projeto de extensão desenvolvido no âmbito do Núcleo de Estudos e Pesquisas em Secretariado Executivo (NEPES) da Universidade Federal do Ceará (UFC).

O NEPES é um programa de Extensão do curso de Secretariado Executivo da UFC que surgiu em 2011 e tem como objetivo:

\begin{abstract}
Incentivar a integração entre a extensão, pesquisa científica e ensino e integrar docentes, discentes e servidores técnico-administrativos por meio de estudos, capacitação profissional, consultoria, pesquisas, eventos, cursos e serviços de extensão voltados ao Secretariado Executivo com foco em: currículo e formação em secretariado, educação em secretariado, assessoria executiva e gestão secretarial (UNIVERSIDADE FEDERAL DO CEARÁ, 2016a, p. 7).
\end{abstract}

Ciente da necessidade de disseminação do conhecimento, o NEPES tem buscado desenvolver ações de extensão e pesquisas cientificas que favoreçam essa realidade na área do Secretariado Executivo. Ressalta-se que esse programa implementa práticas extensionistas que ultrapassam os muros da Universidade, em parceria com órgãos Não-Governamentais (ONG) e instituições educacionais por meio de atividades que envolvem a oferta de cursos na área de Secretariado para a comunidade carente e visitas às escolas da esfera pública, entre outras.

Entre os projetos de extensão vinculados ao NEPES, destaca-se o Secretariado Executivo em Debate, criado em 25 de agosto de 2013 como um meio de discussão sobre temas relevantes ao cotidiano do público-alvo visando, por meio de técnica de análise fílmica trazer variados assuntos para possibilitar uma reflexão de situações que um discente ou profissional de Secretariado Executivo enfrentará na sua convivência acadêmica e profissional (UNIVERSIDADE FEDERAL DO CEARÁ, 2016b).

Um dos temas abordados no âmbito deste projeto refere-se à temática Educação em 
Secretariado Executivo, abordando o impacto da relação de professores com seus alunos e como estes reagem a cada metodologia do ensino empregada seja de maneira autoritária ou de maneira simpática por meio de conversas e oportunidades de discutir opiniões.

Emerge, assim, a questão norteadora deste artigo: quais aspectos podem ser considerados na relação professor-aluno na formação acadêmica?

Este trabalho tem como objetivo relatar um dos assuntos discutidos no projeto de extensão "Secretariado Executivo em Debate" na linha de pesquisa educação em Secretariado Executivo: a afetividade na relação professor-aluno. Como objetivos específicos definiu-se: a) analisar, com base no filme "Ao mestre com carinho 2", a importância da afetividade na relação professor-aluno; b) discutir o impacto do vínculo afetivo para o processo de ensinoaprendizagem, a partir da narrativa do filme "Ao mestre com carinho 2".

Para o alcance dos objetivos propostos, foi selecionado o filme "Ao Mestre com Carinho 2", considerando-se que "[...] a análise fílmica pode ser uma poderosa ferramenta para o fortalecimento do espírito crítico [...]" (SOBREIRA, et. al., 2017, p. 77) do estudante, contribuindo para a formação de futuros profissionais com competência analítica e reflexiva. Destaca-se a relevância deste estudo por possibilitar o compartilhamento de experiências e discussões em torno da temática proposta.

O trabalho está estruturado em cinco seções, além desta introdução. A segunda seção aborda o referencial teórico sobre os efeitos que a relação professor-aluno causa no aprendizado dos discentes. A terceira seção descreve os métodos empregados para alcançar os objetivos propostos. Na quarta seção apresenta-se e análise dos resultados obtidos. Por fim, na quinta seção, são expostas as considerações finais.

\section{O VÍNCULO AFETIVO NA RELAÇÃO PROFESSOR-ALUNO NA EDUCAÇÃo SUPERIOR}

O vínculo afetivo na relação professor-aluno pode impactar nos resultados do processo de ensino-aprendizagem. $\mathrm{Na}$ atualidade, notam-se dois tipos de exemplos de relação dos professores com os alunos, em termos interpessoais, que são o estilo autoritário advindo do ensino tradicional e o democrático com uma relação mais aberta e maior 
proximidade, pois o ponto central do processo educativo é a interação do professor com seus alunos (ABREU; MASETTO, 1990).

Nessa perspectiva, percebe-se que os professores têm procurado promover a superação do modelo tradicional autoritário na relação professor-aluno que imperou por muitos anos nas práticas pedagógicas e ainda poder ser percebido em alguns contextos de ensino, desde os níveis fundamentais aos superiores. Tal prática tem sido considerada como eficaz por tomar como ponto de partida a convivência sociocultural e psicológica do aluno para que ele se desenvolva num processo comunicativo-facilitador da construção de conhecimentos.

A tendência que se verifica é que os professores optam em continuar com uma relação aberta, harmoniosa e de interação mútua pois esses profissionais acreditam que pode existir autoridade sem autoritarismo; todavia, esse exercício pressupõe dificuldades inerentes às relações de caráter assimétrica nas práticas pedagógicas (RONCAGLIO, 2004). Dessa maneira verifica-se que pode haver respeito mútuo entre professor e aluno à medida que pressupõe ser essa relação assimétrica e permeada de autoridade.

Isso vai de encontro ao pensamento de Bohoslavsky (1981 apud RONCAGLIO, 2004, p. 108), que vê o vínculo "natural” de dependência. Com isso, por mais que seja aberta e flexível a comunicação com o professor e que ele se apresente como um facilitador da aprendizagem, a relação professor-aluno vai possuir autoridade e assimetria mesmo num contexto democrático. Todavia, não se deve esquecer que o limite entre autoridade e o exercício do poder pelo saber é bastante tênue e vai depender da profundidade da consciência e da prática pedagógica de cada docente (RONCAGLIO, 2004).

De acordo com Libâneo (2004) o antigo ensino conhecido como verbalista definitivamente não subsiste mais, pois é necessária uma relação mais ativa do aluno com a matéria considerando as experiências da sua trajetória. Os docentes devem possibilitar espaço para que os educandos expressem suas opiniões e sentimentos de modo que tragam para a sala de aula suas realidades vividas, ação conhecida como mediação pedagógica. Dessa maneira, os alunos podem se tornarem sujeitos pensantes, de modo que consigam aprender a usar sua capacidade de pensamento através de meios cognitivos de construção e reconstrução de conceitos, habilidades e valores. Tal combinação mostra-se bem-sucedida da 
assimilação consciente e ativa desses conteúdos com o desenvolvimento cognitivo e afetivo dos alunos.

$\mathrm{Na}$ concepção piagetiana o sujeito busca o equilíbrio por meio da assimilação e adaptação, ao ponderar:

Levando em conta, então, esta interação fundamental entre fatores internos e externos, toda conduta é uma assimilação do dado a esquemas anteriores (assimilação a esquemas hereditários em graus diversos de profundidade) e toda conduta é, ao mesmo tempo, acomodação destes esquemas a situação atual. Daí resulta que a teoria do desenvolvimento apela, necessariamente, para a noção de equilíbrio entre os fatores internos e externos ou, mais em geral, entre a assimilação e a acomodação (PIAGET, 2011, p.89).

Compreendendo-se assimilação ativa como a capacidade que o aluno possui de apropriar-se de forma autônoma dos conhecimentos, levando-o ao desenvolvimento de habilidades e práticas, pode-se inferir que no processo de aprendizagem, o aluno busca um equilíbrio entre os conhecimentos e as experiências que possui e as novas informações externas possibilitando a construção de novos saberes. É nesse contexto que emerge a afetividade na relação professor-aluno, proporcionando um vínculo entre ambos capaz de favorecer o processo de ensino-aprendizagem. Assim, "[a]tores do processo de aprendizagem, aluno e professor devem estabelecer uma relação de confiança e de afetividade na sala de aula para que haja condições reais de aprendizagem. " (ALMEIDA, 2015, p. 6). Nesse sentido, o ensino deve ser entendido como:

[...] uma ajuda ao processo de aprendizagem. Ajuda necessária, porque sem ela é muito pouco provável que os alunos cheguem a aprender, e a aprender da maneira mais significativa possível, os conhecimentos necessários para seu desenvolvimento pessoal e para sua capacidade de compreensão da realidade e de atuação nela. Entretanto, só ajuda, porque o ensino não substitui a atividade mental construtiva do aluno, nem ocupa seu lugar (ONRUBIA, 1994 apud LIBÂNEO, 2004, p. 13).

A interdisciplinaridade pode favorecer o processo de aprendizagem por superar a fragmentação e a compartimentalização para se compreender melhor a realidade Para Japiassu (1976 apud LIBÂNEO, 2004), nesta prática podem ser incorporados os resultados de várias especialidades, tomando-lhes de empréstimos esquemas conceituais de análise e técnicas metodológicas, pois dessa maneira, se espera ultrapassar a especialização excessiva para uma maior ligação entre teoria e prática da ciência com suas aplicações.

Com isso, o professor poderá auxiliar seus alunos a pensar de uma forma crítica, que é a capacidade de aplicar conceitos como forma de apropriação dos conhecimentos, a partir de um enfoque da realidade. Para Libâneo (2004), trata-se de uma abordagem crítica social 
dos conteúdos em que os objetos do conhecimento são apreendidos nas suas propriedades e, ao mesmo tempo, nas suas relações com outros fatos da realidade, incluindo especificamente as ligações e nexos sociais que os constituem como objetos do conhecimento. É pela apropriação crítica da realidade que se pode contextualizar um tema de estudo para buscar compreender suas ligações com a prática humana. Nessa direção, considera-se que:

Quando o professor ensina um tema, uma matéria, ele deveria perguntar a si próprio e aos alunos: como os homens e mulheres, na sua atividade prática coletiva nas várias esferas da vida social, intervêm, modificam, constroem, esse tema de estudo? Qual é a sua importância para atender ás necessidades práticas da vida social, como os problemas sociais, o desenvolvimento da ciência e da tecnologia, as necessidades humanas básicas? O que este tema tem a ver com as contradições sociais, com as desigualdades sociais, com a dinâmica das relações entre grupos e classes sociais? (LIBÂNEO, 2004, p. 38).

É imprescindível destacar o impacto de tal relação na dimensão afetiva dos discentes, pois toda aprendizagem envolve sentimentos e emoções ligados tanto às relações familiares quanto no meio profissional. No âmbito educacional, para que essa relação se desenvolva é fundamental que:

[...] aluno e professor mantenham esta relação baseados no diálogo, pois através dele é possível a troca de ideias, dúvidas e até mesmo sentimentos, fazendo com que aluno e professor se conheçam e se compreendam melhor, utilizando de suas diferenças para qualificar seu vínculo e carregá-lo de afeto. (ALMEIDA, 2015, p. 7).

Dessa maneira, torna-se relevante para o professor conhecer e compreender as motivações e interesses do aluno, bem como sua capacidade de comunicação com o mundo de cada um dos discentes. O papel educacional consiste em aliar conhecimentos a convicções para conviver com os dilemas da vida. Portanto, os professores devem repassar os valores norteadores para a vida prática. "Não se trata, obviamente, de inculcar valores, de doutrinação política ou religiosa, mas de propiciar aos alunos conhecimentos, estratégias e procedimentos de pensar sobre valores e critérios de modos de decidir e agir". (LIBÂNEO, 2004, p. 46).

A relação afetiva entre professor e aluno na universidade surge como um importante tema a ser discutido, considerando-se que a experiência vivenciada sempre será de uma responsabilidade maior do que os níveis da educação básica. Dessa maneira, aumenta-se o questionamento sobre algumas respostas do professor ao chamado do educando, desenvolvendo seu senso crítico que é uma habilidade importantíssima na educação superior. A maneira como o professor e o aluno se relacionam pode ser crucial para uma tomada de decisão eficaz para ambos. Na próxima seção apresentam-se os caminhos metodológicos 
percorridos para o desenvolvimento desta pesquisa.

\section{MATERIAIS E MÉTODOS}

O presente trabalho é resultado da vivência na organização do encontro de estudos, por meio de análise fílmica, como uma das ações do projeto de extensão "Secretariado em Debate" no âmbito do Núcleo de Estudos e Pesquisas em Secretariado Executivo (NEPES) do Curso de Secretariado Executivo da Universidade Federal do Ceará (UFC). Para a realização das atividades de extensão do NEPES há uma subdivisão dos seus componentes em subgrupos, denominados de células, coordenados por professores do Curso, a saber: educação em Secretariado Executivo, estudos organizacionais e gestão secretarial, gestão de pessoas e empreendedorismo, gestão secretarial e assessoria executiva, pesquisa em Secretariado Executivo (UNIVERSIDADE FEDERAL DO CEARÁ, 2016a).

Este estudo desenvolveu-se por meio de encontros da "célula" do NEPES que aborda a educação em Secretariado Executivo e foi responsável pela discussão acerca do tema ora discutido, no projeto "Secretariado Executivo em Debate". Para tanto, foram realizados encontros dos quais participaram dois estudantes e três docentes que compõem esse grupo de trabalho no NEPES.

Trata-se de uma pesquisa qualitativa, tendo como estratégia o estudo observacional indireto que, segundo Machado e Matos (2012, p. 12), realiza um exame minucioso de comportamentos ou atividades "[...] a partir de dados documentados, como é o caso das narrativas fílmicas". Foi selecionado o filme "Ao mestre com carinho 2"; esta decisão se deu pelo fato de que o seu roteiro relata a trajetória de um professor que, ao superar diversos desafios com a turma na qual leciona, ao longo da história, estabelece vínculo afetivo na sua relação com os estudantes. Quanto aos materiais, reportou-se aos trechos do filme e sínteses, seguidos de um debate.

O estudo observacional ocorreu em quatro momentos fundamentados nas etapas de investigação e aplicação propostos por Machado e Matos (2012):

a) construção da questão ou objetivo de pesquisa: planejamento do encontro do Secretariado em Debate no qual foi feita a definição do tem, e do objetivo;

b) busca e seleção da fonte de dados narrativos: escolha do filme a ser analisado; 
c) visão geral da narrativa do filme: nesse momento os participantes assistiram ao filme completo;

d) decupagem ${ }^{1}$ dos dados (cenas e falas): seleção das cenas que seriam analisadas; e) fundamentação e interpretação dos dados: levantamento e estudo teórico a ser relacionado ao filme.

Realizou-se leitura e discussão do filme à luz da teoria em torno dos objetivos deste trabalho; e

e) produção do relatório final: conclusão do relatório do estudo desenvolvido.

A análise foi desenvolvida a partir do referencial teórico, relacionando-o às cenas selecionadas para este estudo, destacando-se as falas dos participantes durante a discussão. Os resultados e discussões são abordados na seção a seguir.

\section{RESULTADOS E DISCUSSÕES}

\subsection{SOBRE O NEPES E O SECRETARIADO EXECUTIVO EM DEBATE}

O NEPES é uma ação de extensão cuja modalidade se identifica como programa, que é um conjunto de atividades integradas, de médio e longo prazo, orientadas a um objetivo comum, articulando projetos e outras atividades de extensão, cujas diretrizes e escopo de interação com a sociedade, integrem-se as linhas de ensino e pesquisa desenvolvidas na UFC, nos termos de seus projetos políticos pedagógicos e de desenvolvimento institucional. A sua importância reside no fato de que a pesquisa e a extensão são meios de "proporcionar aos egressos do curso de Secretariado executivo da UFC um ensino de qualidade, capacitando-os para o exercício pleno das funções de assessoria nas mais diversas organizações, enfatizando o desenvolvimento de habilidades e competências inerentes a prática profissional, potencializando seu desenvolvimento pessoal e compreendendo os fenômenos do universo empresarial” (UNIVERSIDADE FEDERAL DO CEARÁ, 2006a, p. 14). Ressalta-se a relevância da criação de um núcleo de pesquisas e estudos direcionado a área secretarial por meio de atividades extensionistas.

\footnotetext{
${ }^{1}$ O termo “decupagem" significa variação, assincronia.
} 
Dentre os objetivos específicos destacam-se: desenvolver estudos, capacitação profissional, pesquisas, eventos, cursos e serviços de extensão em Secretariado Executivo; transmitir os resultados à comunidade acadêmica e à sociedade sobre os desafios e as possibilidades da área secretarial por meio de eventos e ações extensionistas. Ao longo do desenvolvimento deste programa (NEPES) têm sido realizadas atividades de pesquisa com publicações em eventos e revistas cientificas, a organização de eventos acadêmicos para a comunidade interna e externa e ações de extensão junto à sociedade.

Um dos projetos de extensão desenvolvidos no âmbito do NEPES é o Secretariado Executivo em Debate, o qual possui caráter educativo, social, cultural, cientifico e tecnológico. Sua criação surge da necessidade de preenchimento da lacuna sobre a pouca carga horaria da prática secretarial, utilizando a metodologia da análise fílmica como forma de refletir sobre as possíveis situações que um discente ou profissional de Secretariado Executivo enfrentará em seu cotidiano acadêmico e profissional. Tais situações observadas em obras fictícias e analisadas à luz de teoria específica podem favorecer a percepção crítica e reflexiva. Seu credenciamento é gratuito, feito no local e fornece certificado de participação que considerada como horas de atividades complementares. (UNIVERSIDADE FEDERAL DO CEARÁ, 2016b). Podem participar discentes do Curso de Secretariado Executivo, docentes, profissionais e demais interessados nos temas, mantendo assim, um diálogo entre a Universidade e a comunidade interna e externa.

\subsection{O ESTUDO OBSERVACIONAL: ANÁLISE DO FILME "AO MESTRE COM CARINHO 2"}

O filme “Ao mestre com carinho 2" foi lançado em 1996, estrelado por Sidney Poitier. Apesar de abordar um tema bastante discutido e polêmico, a trama se concentra nos padrões da adolescência em uma comunidade carente em Chicago. Narra um drama vivido por um engenheiro que se tornou professor e, após lecionar durante 30 anos em Londres, aceita o desafio de, em uma escola pequena, assumir uma turma considerada como problemática pelo diretor Florian (Edward Burnham) e demais professores. Mr. Weston (Geoffrey Bayldon) evidencia desprezo em relação aos estudantes, Gillian Blanchard (Suzy 
Kendall) admite temer assumir a turma e Head Evans (Faith Brook) ressalta que os jovens são oriundos de lares problemáticos.

Os estudantes da turma são considerados como adolescentes indisciplinados, rebeldes, desajustados, fora dos padrões normais de comportamentos. Isso é constatado pelo professor, que identifica entre os alunos o uso de drogas, armas, prostituição e brigas entre gangues. Na escola, existe uma área específica para alunos com esse perfil, denominado Setor H.

A primeira cena analisada narra o primeiro dia de aula demonstra que o professor se depara com alunos totalmente indisciplinados levando-o a usar sua autoridade pedindo para que se sentem, além de proibir a evasão da sala de aula. Em seguida, o professor procura ensinar-lhes a respeitá-lo ao solicitar que os alunos se portem a ele como Sr. Thackeray. Nesse intuito, mantém uma conversa respeitosa com os alunos e se nega a dirigir-se a eles por seus apelidos, preferindo chamar-lhes pelo nome.

Percebe-se que o uso da autoridade não foi suficiente para manter a ordem em sala de aula, visto que, logo em seguida, a turma volta a bagunçar o local e não demonstra o menor respeito à figura do educador. Nessa direção, destaca-se que Foucault (1979 apud RONCAGLIO, 2004) considera a relação entre saber e poder como um aspecto presente na contemporaneidade; observa-se que o professor Thackeray tenta utilizar o poder para impor respeito, sem sucesso naquela turma.

No decorrer das aulas, o professor Thackeray busca, de todas as maneiras, manter a postura equilibrada, a calma e o respeito com os discentes. No entanto, com a crescente hostilidade e falta de subordinação por parte de todos os alunos, destaca-se a segunda cena analisada na qual certo dia, o professor ordena que os rapazes saiam da sala de aula, e adverte asperamente as jovens por seu comportamento. Esta postura denota que o docente, ao não conseguir coagir os estudantes a obedecê-lo por meio do poder, perde o autocontrole mediante a turma.

Preocupado com sua atitude, desgostoso com sua postura extremamente radical, expressando seu descontentamento, resolve mudar sua atitude perante a classe. Nessa proposta de rever, de refletir e de organizar sua ação a partir da articulação da ação-reflexãoação, o professor retorna a classe e estabelece novas regras, tentando uma nova 
aproximação. A partir desse momento, a atitude do professor é fundamentada em uma nova forma de relação professor-aluno, baseada na criação de vínculo afetivo. Para Fazenda (1994 apud LIBÂNEO, 2004), isso significa eliminar não só as barreiras entre as disciplinas, mas também as barreiras entre as pessoas por meio de trocas de conhecimentos e experiências entre si. Suas formas de visualização consistem em reunir conteúdos que permitem tratamento pedagógico-didático interdisciplinar e formular conhecimento, após levantamento de características da realidade local e da identificação de problemas mais significativos para os alunos com assuntos geradores que possibilitem a compreensão mais globalizante dessa realidade.

Um exemplo de estabelecimento de vínculo afetivo ocorre na cena em que o aluno Wilsie porta uma arma de fogo no interior na escola e o professor, ao descobrir, o interpela por meio do diálogo, convencendo o estudante a entregá-lo a arma espontaneamente. Em troca, o professor se compromete a não o denunciar, afirmando que não quer causar-lhe nenhum problema. Wilsie entrega a arma nas mãos do professor, demonstrando acreditar em sua promessa, ou seja, foi estabelecido um vínculo com base na confiança.

Outro momento marcante da relação professor-aluno por meio do laço afetivo pode ser identificado na cena em que o professor estimula uma discussão em sala de aula de forma descontraída sobre os dilemas enfrentados pelos jovens no que se refere às relações sexuais. Nessa conversa, os estudantes indagam ao professor sobre a sua vida sentimental e ele compartilha aspectos da sua vida pessoal, narrando sua história ao ficar viúvo, além de um relacionamento amoroso de quando era jovem.

Tal atitude do professor pode ser relacionada às considerações de Roncaglio (2004), de que se faz necessário o desenvolvimento da comunicação como facilitadora da construção de conhecimentos. Entre os fatores que sustentam este processo ressalta-se a liberdade de expressão, a estruturação de conteúdos adaptados à realidade dos alunos, a flexibilização das normas do contrato didático e a autonomia, guiados por princípios filosóficos humanistas que fazem com que o aluno participe do processo de ensino de uma maneira eficaz e contextualizada.

Como resultado de uma relação mais próxima com os alunos, paulatinamente, ele desenvolve uma mudança na concepção dos educandos, embutindo valores, ensinando 
comportamentos decentes, levando-os ao amadurecimento comportamental e à responsabilidade por suas posturas mediante à sociedade. Nesse sentido, ressalta-se a relevância de os docentes levarem "[...] em conta os sentimentos e emoções de seus alunos e olhar de maneira mais afetiva para suas necessidades, e dessa forma se construirá uma relação positiva entre eles em sala de aula, potencializando o processo de aprendizagem e de ensinagem”. (ALMEIDA, 2015, p. 8).

Em relação ao esforço do docente para convencer os estudantes sobre a necessidade de mudança de atitude perante à sociedade, destaca-se a cena na qual os irmãos Carrouthers indagam que só os colocaram no "setor H", denominação dada à turma composta por alunos indisciplinados, porque a própria diretoria sabe que eles não vão sobreviver no cotidiano da vida deles. Os alunos atribuem a classificação "Setor H" como horror, denotando que as pessoas já possuem opinião formada sobre eles e consideram parte disso como preconceito racial.

O professor Thackeray recomenda que eles devem procurar mudar a postura e adquirir caráter, disciplina, determinação e procurar sobreviver com dignidade, por mais duro que seja o mundo em seu entorno. Em seguida, ele os leva para a rua a fim se mostrar-lhes como terem boa conduta e educação na relação com as pessoas. De acordo com Libâneo (2004), a contemporaneidade requer das universidades um professor capaz de ajustar sua metodologia didática às novas realidades da sociedade, dos alunos e dos diversos universos culturais.

O trabalho de educação não formal realizado pelo professor, as relações extraclasse e o vínculo afetivo desenvolvido ao logo da narrativa, causam efeito positivo no comportamento dos estudantes tanto na sala de aula quanto em suas vidas pessoais, levandoos, inclusive a ter visão crítica e defender suas ideias. Isso é comprovado quando o professor é demitido da escola por não colaborar com uma investigação policial que envolvia a arma que ele recebeu do aluno Wilsie. O professor, para cumprir a promessa feita ao aluno, não informa o nome de quem lhe entregou a arma.

Ao tomarem conhecimento do ocorrido, os alunos fazem protesto em sala de aula e exigem seu professor de volta, alegando que nunca tiveram um professor de verdade como o Thackeray. Eles usam uma estratégia de resistência pacífica apenas ficando em pé, mas sem 
realizar qualquer confusão e, como resposta, o professor Mark Thackeray conquista seu emprego de volta. Esta narrativa do filme, corrobora a percepção de Almeida (2015, p. 8), ao afirmar:

\begin{abstract}
O trabalho docente baseado na afetividade não é tão fácil e encantador como parece, levando em conta que cada sujeito é único e tem suas próprias opiniões e visão de mundo. Mesmo com as adversidades que possam surgir, é preciso que os professores conheçam melhor seus alunos, se aproximem mais e se dediquem de corpo e alma a suas aprendizagens para que seja possível a formação de seres pensantes e transformadores da sua realidade.
\end{abstract}

Ao final do filme, destaca-se uma cena de formatura na qual o professor Thackeray expõe a realidade de alguns formandos apontando essas transformações. Nesta cena o professor Mark Thackeray está sentado, acompanhando a formatura de seus alunos concluírem do ensino médio. Entre eles destacam-se: La Verne Mariner que se tornou estagiária na campanha do Senador Butler, Evie Hills que está estudando jornalismo e Wilsie Carrouthers que está no Programa Federal de auxílio a ex-integrantes de gangues de rua. Percebe-se que o vínculo afetivo na relação professor-aluno estabelecido por meio das atitudes do professor Mark Thackeray resultou em uma transformação na vida dos estudantes, visto que como "[...] atores do processo de aprendizagem, aluno e professor devem estabelecer uma relação de confiança e de afetividade na sala de aula para que haja condições reais de aprendizagem" (ALMEIDA, 2015, p. 6). No filme analisado, evidencia-se que o vínculo afetivo na relação professor-aluno desenvolvido contribuiu de forma significativa para a melhoria da aprendizagem dos estudantes e para a transformação de suas realidades sociais. A seguir expõe-se a conclusão desta pesquisa.

\title{
5 CONCLUSÃO
}

O estudo observacional do filme "Ao mestre com carinho 2" possibilitou algumas considerações conclusivas acerca dos aspectos que podem ser considerados na relação professor-aluno na sua formação. A análise do filme destacou a importância da afetividade na relação professor-aluno. Sobre esse aspecto, percebeu-se que a aprendizagem de conceitos e valores envolve sentimentos e emoções, ligados aos ambientes sociais nos quais os alunos estão inseridos. Dessa maneira, a análise fílmica denotou que uma abordagem de ensino fundamentada no desenvolvimento de um vínculo afetivo entre professor e aluno, por meio da 
abertura e com maior interação, possibilita o desenvolvimento de sua capacidade pensante.

Quanto ao impacto do vínculo afetivo para o processo de ensino-aprendizagem, a partir da narrativa do filme "Ao mestre com carinho 2 e das reflexões realizadas", infere-se que na medida em que o professor busca conhecer melhor o educando, demonstra preocupação em relação ao seu futuro e o educa por meio de exemplos de fidelidade, conquista a confiança. Um dos pontos mais característicos abordados na narrativa é o papel do diálogo no desenvolvimento do ser humano. Por meio do diálogo, alunos e professores aprendem a se conhecerem melhor e desenvolverem a afetividade entre ambos, contribuindo para o processo de ensino-aprendizagem. Onde há afeto, há maior interação, compromisso e construção de caráter.

No processo de ensino-aprendizagem pode ocorrer maior interesse por parte do aluno em buscar novos conhecimentos, bem como o desenvolvimento de um senso crítico com base no respeito para com todas as pessoas. Verifica-se que o desenvolvimento afetivo entre professor-aluno pode ser preponderante para o seu desenvolvimento como pessoa segura e autônoma em suas relações. Esta discussão contribui para a formação do profissional de Secretariado Executivo, por apresentar subsídios que possibilitem aos docentes e discentes reflexões acerca do impacto da relação professor-aluno para o processo de ensinoaprendizagem, bem como a busca por metodologias que promovam a formação de profissionais críticos e transformadores do seu entorno. Por outro lado, os docentes que participaram da discussão denotaram que sua formação não aborda conhecimentos pedagógicos, porém, sentem a necessidade de desenvolver uma relação mais próxima com os alunos.

Conclui-se, portanto, que o filme retrata os desafios que o professor pode enfrentar para contribuir para a formação intelectual e humana dos alunos, destacando que a afetividade na relação professor-aluno pode ser fator preeminente para os processos de ensinar e aprender, de modo que o aluno seja capaz de transformar a sua realidade e, consequentemente, a sociedade.

\section{REFERÊNCIAS}

ABREU, Maria. Cecília de.; MASETTO, Marcos Tarcísio. O professor universitário em 
aula: prática e princípios teóricos. ed. 8. São Paulo: MG Editores Associados, 1990.

ALMEIDA, Yndyne Francyane Silva de. O vínculo afetivo e suas contribuições para a relação professor-aluno. XI Semana de Extensão, Pesquisa e Pós-Graduação - SEPesq Centro Universitário Ritter dos Reis. Anais... Porto Alegre, 2015. Disponível em:

https://www.uniritter.edu.br/files/sepesq/arquivos_trabalhos/3611/710/862.pdf. Acesso em: 18 set. de 2017.

BARROS, C.M.P.; SILVA, J.S.; BARROS, A.P.C.H. Ensino com pesquisa: contribuições para a cientificidade na formação em secretariado executivo. Revista de Gestão e Secretariado - GeSec. São Paulo, v. 7, n. 1, p. 67-84,2016. Disponível em: https://www.revistagesec.org.br/secretariado/article/view/411. Acesso em: 6 fev. 2018.

BARROS, C.M.P.; SILVA, J.S.; DIAS, A.M.I (Orgs). Secretariado executivo e educação: temas que se articulam pela formação, docência na educação superior e pesquisa científica. Fortaleza: Edições UFC, 2016.

LIBÂNEO, Jose Carlos. Adeus professor, adeus professora? novas exigências educacionais e profissão docente.-8.ed.-São Paulo: Cortez, 2004.

MACHADO, Diego de Queiroz Machado.; MATOS Fátima Regina Ney. Estudos observacionais em linguagem fílmica. Curitiba: CRV, 2012.

NÓBREGA, V. S.SC.; ADELINO, F.J.S. A inclusão do docente de secretariado executivo em programas de pós-graduação stricto sensu: um estudo realizado junto à plataforma Lattes do CNPq. Revista do Secretariado Executivo. Passo Fundo, p. 76-88, n. 8, 2012. Disponível em: http://seer.upf.br/index.php/ser/article/view/3027/2033. Acesso em: 6 fev. 2018.

PIAGET, Jean. Seis estudos de Piaget. 25 ed. Rio de Janeiro: Forense Universitária, 2011.

RONCAGLIO, S. M. A Relação Professor-Aluno na Educação Superior: A Influência da Gestão Educacional. Revista: psicologia ciência e profissão. Brasília, V.24, N.2, p. 100-111, 2004. Disponível em: <http://www.scielo.br/pdf/pcp/v24n2/v24n2a11.pdf. Acesso em: 15 set. de 2017.

SOBREIRA et. al. Estudo observacional sobre o fascismo na sociedade moderna à luz do filme “A onda". In: MATOS, Fátima Regina Ney.; MESQUITA, Rafael Fernandes de.; MACHADO, Diego de Queiroz. (OrgS). Estudos observacionais em linguagem fílmica ética e poder. Curitiba: Editora Prismas, 2017.

UNIVERSIDADE FEDERAL DO CEARÁ. Programa de extensão Núcleo de Estudos e Pesquisas em Secretariado Executivo - NEPES. Formulário de cadastro da ação de extensão. 2016a.

Projeto de extensão: Secretariado em Debate. Formulário de cadastro da 
ação de extensão. 2016 b. 